Шиян Т. А. О трактовке философии и науки как «знания» в контексте их онтологической характеристики // Философия. Журнал Высшей школы экономики. - 2017. - Т. I, № 3. - C. $80-104$.

\title{
TAPAC Шиян*
}

\section{О ТРАКТОВКЕ ФИЛОСОФИИ И НАУКИ КАК «ЗНАНИЯ》В КОНТЕКСТЕ ИХ ОНТОЛОГИЧЕСКОЙ ХАРАКТЕРИСТИКИ**}

\begin{abstract}
Аннотация: Первым и самым важным шагом при определении любых объектов мышления является указание, к какому типу объектов уже известной природы относится данный объект. В общем случае эту операцию можно назвать «отнесением к роду», а в случае, когда она используется с целью задания или прояснения онтологического статуса некоторого объекта, - «онтологическим отнесением». Через призму этой онтологической операции рассматриваются обсуждения природы и генезиса математики, а также философии и науки в целом. В литературе встречаются четыре основные трактовки природы философии, науки в целом и их частных дисциплин: отнесение их к знаниям (о том или ином предмете), к совокупностям или системам знаний, к видам деятельности и к областям, сферам, системам деятельности (социальным институтам). Каждая из этих интерпретаций связана с принятием своих онтологических и гносеологических предпосылок, а также ряда эмпирических следствий относительно времени, места, цивилизационного и историко-культурного контекста и других обстоятельств возникновения философии, математики, других наук и науки в целом. В центре внимания статьианализ предпосылок и следствий, связанных с первой из четырех основных трактовок природы философии и науки - интерпретацией их как знания. Эта трактовка наиболее распространена, но, как правило, не формулируется в текстах эксплицитно-несмотря на то, что она связана с принятием наиболее сильных онтологических предположений (о внекультурных и внеисторических формах существования знаний) и наиболее радикальных историко-культурных выводов (о существовании философии и науки во всех человеческих сообществах и во все времена).
\end{abstract}

Ключевые слова: наука, математика, онтология, отнесение к роду, онтологическое отнесение, знание, область знания, сфера деятельности, социальный институт, первобытное общество.

*Шиян Тарас Александрович, к. филос. н., доцент кафедры социологии управления философско-социологического факультета Института общественных наук Российской академии народного хозяйства и государственной службы при Президенте Российской Федерации (Москва); доцент кафедры философии богословского факультета Православного Свято-Тихоновского гуманитарного университета (Москва), taras_a_shiyan@mail.ru.

** (C) Шиян, Т. А. (C) Философия. Журнал Высшей школы экономики. 
МЕТОДОЛОГИЧЕСКОЕ ВЕДЕНИЕ:

ОТНЕСЕНИЕ К РОДУ КАК ЛОГИЧЕСКАЯ ОПЕРАЦИЯ

И КАК ОНТОЛОГИЧЕСКАЯ ХАРАКТЕРИСТИКА

Важной для теоретической деятельности операцией, проясняющей смысл языковых выражений и иных знаков, является операция отнесения $\kappa$ роду - указание на то, к какому более широкому и уже известному классу объектов принадлежит проясняемый предмет. Она, хоть и не имеет специального названия, широко используется в логике, философии и методологии. В частности, эта операция является составной частью другой, более сложной логической операции-родовидового определения, которое состоит из отнесения к роду и указания отличительных (внутри данного рода) признаков. По странному стечению обстоятельств, даже те учебники логики, которые уделяют место разбору не только определений, но и других способов прояснения знаковых выражений, проходят мимо данной операции. Возможно, это связано с тем, что вне выполнения некоторых специфических логических и онтологических функций эта операция может восприниматься как частный случай характеристики, а в рамках теоретико-множественного мировоззрения даже выделение «характеристики» как особой проясняющей операции является излишним, поскольку все это может быть представлено как варианты операции отнесения $\kappa$ множеству.

$\mathrm{C}$ точки зрения методологической функции можно выделить два особых случая операции отнесения к роду. В первом случае отнесение к роду используется для разграничения уже известных смыслов и является одним из возможных способов осуществления операции различения ${ }^{1}$ (а именно является различением через родовое отнесение). Например: «Мы говорим о философии как о сфере деятельности, а не как об учении или системе взглядов какого-то конкретного человека или группы людей». Здесь операция различения проводится через различение родов $X$ и $Y$, к которым относятся разные предметные значения слова «философия».

Во втором случае операция отнесения к роду есть указание на то, к какому более широкому классу объектов уже известной природъ принадлежит проясняемый объект (объекты). В этом случае операция

${ }^{1}$ Различение (дистинкиия) - другая важная, но тоже игнорируемая современными учебниками логики операция прояснения, хотя в традиционной (например, средневековой европейской) диалектике проведение дистинкций было важным инструментом прояснения смысла языковых выражений и разрешения споров. 
задает онтологическую рамку: как мыслить о проясняемом предмете, к какому типу уже известных объектов он принадлежит, - то есть она выполняет функцию онтологической характеристики предмета. Для отличения этого варианта родового отнесения от других его можно назвать онтологическим отнесением.

Операция онтологического отнесения осуществляется, например, в основаниях математики при построении всей системы математического знания как развитии одной базовой теории. В терминах этой теории, играющей при этом роль формальной онтологии, переинтерпретируются все типы математических объектов- индивиды, множества, функции, отношения, свойства и т.д. Так, первым вариантом единой онтологии современной математики стала теория множеств, в рамках которой все математические объекты были проинтерпретированы как множества того или иного вида. Позже в качестве другого варианта единой онтологии была предложена теория функций, в рамках которой все математические объекты трактуются, соответственно, как функции того или иного вида. Существуют и иные теории, которые по своим выразительным возможностям могут играть роль единой онтологии математики. Соответственно, в зависимости от того, какая теория будет избрана в качестве основания математики, все математические объекты получат свою трактовку как множества, функции и т. д., то есть выбор той или иной базовой теории сопряжен с соответствующим онтологическим отнесением. В зависимости от этого изменяется не только концептуализация соответствующих объектов (например, натуральных чисел как множеств, как функций и т.д.), но и методы работы с ними.

\section{ПРОБЛЕМА ОНТОЛОГИЧЕСКОГО ОТНЕСЕНИЯ ФИЛОСОФИИ И НАУКИ}

Онтологическое отнесение является основой любой теоретической деятельности и играет особенно важную роль в случае объектов, которые целиком могут быть ухвачены или построены только мысленно, концептуально. К таким объектам относятся философия, наука в целом, различные частные науки, включая математику, а также многочисленные входящие в их состав философские и научные дисциплины. В зависимости от того, к какому типу сущего наука будет отнесена, мы получим принципиально разные мыслительные объекты. Так, философия, наука и составляющие их частные дисциплины разными авторами 
относятся к знаниям о том или ином специфическом предмете; к cuстемам, или относительно оформленным совокупностям знаний, со своим специфическим предметом, а также, возможно, структурой, методом и т. д.; к видам деятелъности, обычно тоже определяемым по предмету, но иногда также и по некоторым другим характеристикам; к особым образом оформленным, организованным сферам деятельности, коммуникации, социалъной жизни ${ }^{2}$.

Два наиболее общих направления решения вопроса о природе философии и науки - отнесение их к сфере эпистемического (знание, система знаний) или к сфере социального (деятельность, сфера деятельности). Оба типа отнесения можно найти, например, в разных определениях математики, представленных в обзорной книге итальянского философа математики Г. Лолли «Философия математики. Наследие двадцатого столетия». В ней приводятся следующие эпистемические варианты родового отнесения математики: «Математика - это знание...» (Лолли, Сочков и Антаков, 2012: 73), «Математика-скорее не метод и не искусство. Это совокупность знаний, содержание которых...» (Kline, 1953; цит. по: Лолли, Сочков и Антаков, 2012: 73). Вариантов деятельностного отнесения больше: «Математика представляет собой публичную деятельность, которая...» (Goodman, 1979; цит. по: Лолли, Сочков и Антаков, 2012: 71), «В случае с математикой этимология сообщает нам только, что математика есть изучение, деятельность, направленная на изучение, но чего-не уточняет» (Лолли, Сочков и Антаков, 2012: 92), «Математикаэто изучение...» (там же: 71-72), «Математика-это конструирование...» (там же: 72 ). Примеры скорее деятельностной, чем эпистемической, трактовки можно найти в книге «Прелюдия к математике» африканского математика У. У. Сойера:

...однажды кто-то, видимо, в отчаянии предложил определить математику как «все, чем занимаются математики». Казалось, что только такое широкое определение может охватить все, что относится к математике. [...] Точнее было бы определение: «Математика-это классификация всех возможных задач и методов их решения». Это определение, пожалуй, тоже расплывчато [...] Для целей нашей книги достаточно было бы определение: «Матема-

${ }^{2}$ Такие области я обозначаю термином «социальный институт», хотя существуют и иные типы, и иные трактовки социальных институтов. Для отличения данного понятия социальных институтов от иных можно называть их «сферными». 
тика - это классификация и изучение всех возможных закономерностей» 3 (Сойер, Смолянский и Романова, 1972: 7).

При общей эпистемической трактовке оба плана - эпистемический и деятельностный - присутствуют и в «Кратком очерке истории математики» Д. Я. Стройка (Стройк, Погребысский, 1984), который более подробно анализируется ниже. И даже А.Л. Никифоров в книге «Философия и история науки», определяя науку в целом как «сферу человеческой деятельности» (что совпадает с моим пониманием философии и науки), все же добавляет: «Наука-это и деятельность по приобретению знаний, и вся сумма накопленного знания» (Никифоров, 2008: 37). Этот дуализм понятен: с одной стороны, философия, наука в целом и их многочисленные более частные дисциплины - явления социальные и, следовательно, существующие только в деятельности и через деятельность; с другой стороны, особенность философии и наук состоит в выработке, накоплении и передаче «знаний».

Но этого различения явно не достаточно. Так, из двух приведенных выше вариантов эпистемического отнесения математики (из книги Лолли) в одном она трактуется как некоторое знание, во втором - как совокупность (возможно, лучше было бы сказать «система») знаний. Это два разных онтологических отнесения, связанных с разными онтологическими предпосылками, разными решениями вопроса о времени и условиях возникновения, а также с другими выводами. Эти две эпистемические трактовки являются существенными и для прояснения онтологического статуса остальных наук, философии, а также составляющих их частных дисциплин. Для деятельностных трактовок философии и науки существует два аналогичных варианта: их можно трактовать как некоторого вида деятельность (сюда относятся приведенные выше из книги Лолли деятельностные трактовки математики) и как определенного вида системы деятельности. При этом системы деятельности в данном контексте часто рассматриваются «изнутри», как некоторым образом организованные области, сферы, пространства деятельности, коммуникации, социальной жизни,- как, например, в упомянутой выше книге

${ }^{3}$ Используемое автором слово «классификация» (classification) может обозначать как деятельность по классификации, так и ее результат. Использование именно этого слова, а не возможного «классифицирование» (classifying), указывает здесь на возможность и частично эпистемической трактовки. 
Никифорова: «Науку обычно определяют как сферу человеческой деятельности, направленную на получение, обоснование и систематизацию истинного знания о мире» (Никифоров, 2008: 37).

На мой взгляд, система таких областей составляет первичную основу социальной и смысловой организации общества, задает смысловое и функциональное (деятельностное) деление «жизненного мира» людей на сферы деятельности, предметные регионы и т. п. Соответственно, онтологически первичным является существование философии, науки и их частных дисциплин именно в качестве социальных институтов (в указанном выше смысле этого термина), и только в процессе и в рамках их институционального оформления происходит деление «мира»на соответствующие предметные области, формируются системы знаний об этих предметах, выделяются особые виды деятельности, характерные для того или иного социального института. В силу этого, с одной стороны, все остальные аспекты философии и науки (специфика знаний и их организации, характерные виды деятельности и т. п.) доступны анализу в рамках институционального подхода, а с другой, именно институциональный подход задает рамку для корректного философского анализа знаний и деятельности.

Отнесение философии или какой-либо конкретной науки к знанию, к системе знаний, к деятельности или к сфере деятельности меняет не просто «точку зрения» на объект-оно меняет сам объект мышления и, более того, меняет тип этого объекта, связанный со способом его существования. Вместе с этим изменяются не только теоретические характеристики объекта, но и вполне эмпирически фиксируемые следствия. В зависимости от принятия того или иного родового отнесения решение проблемы генезиса философии и науки варьирует по типу цивилизации, в которой эти явления впервые появляются, по времени их возникновения, по их национально-культурной локализации и т. д. Например, в зависимости от родового отнесения «науки» к знанию или к социально оформленным сферам деятельности (социальным институтам) датировка периода ее становления смещается от палеолита до Нового времени, а цивилизационный и культурный контекст-от любых (для некоторых наук) догосударственных, родоплеменных сообществ с технологиями древнего каменного века до европейского индустриального капитализма XVIII - начала XX в.

Но принятие решения о том или ином родовом отнесении философии и науки не только влечет использование разного инструментария исследования и кардинально разные решения о времени и условиях их 
возникновения, но и связано с принятием определенных онтологических и гносеологических предпосылок. В частности, рассмотрение философии и науки как знания, как системы знаний или как вида деятельности требует принятия определенных онтологических предпосылок натуралистического характера, например, о существовании видов знаний или деятельности самих по себе, вне исторического контекста, конкретных форм их организации и т. п. Философская приемлемость или неприемлемость этих предпосылок задает границы и для философской приемлемости или неприемлемости принятия того или иного родового отнесения и основанного на нем определения. Отказ от принятия предпосылки о заранее заданной расчлененности мира на «регионы» математического, физического, химического, биологического и т. д. приводит нас к вопросу о практиках (в том числе познавательных), задающих то или иное предметное членение «мира». Отвержение предпосылки о самостоятельном, независимом, первичном онтологическом существовании знаний или систем знаний снова приводит к вопросу о практиках, в рамках которых формируются эти знания или системы знаний. Аналогично, отвержение предпосылки о самостоятельном, независимом, первичном онтологическом существовании видов деятельности приводит к вопросу о практиках или системах деятельности, с которыми связано их формирование. Данная статья посвящена анализу предпосылок и выводов, связанных с принятием первого из указанных выше основных онтологических отнесений философии и науки - с трактовкой их как «знания».

В завершение этой части подчеркну еще раз, что не всякое формально проведенное родовое отнесение проясняет онтологический статус объекта. Каким бы парадоксальным с точки зрения традиционной логики это ни показалось, в некоторых случаях слишком неоднозначная онтологическая трактовка может возникать из-за отнесения объекта к слишком узкому роду. Следуя традиции современной логики, я использую здесь слова «универсум», «род»и «вид» функционально, в контексте осуществления некоторых логических операций (родовидового определения, ограниченного принципа свертки в теории множеств, привязки логического анализа к определенной предметной области и т. п.). В отличие от этого, в прошлом данные понятия имели онтологический статус, и структура «универсума» задавалась достаточно жестко устоявшейся иерархией «родов» и «видов». В этой ситуации для родовидовых определений существовало требование определения через ближсайший род и видовое отличие. В современной ситуации отсутствия единой иерархической картины мироздания это требование оказывается не только 
излишним, но и вредным, создавая иллюзию проясненности там, где ее нет. Так, выше были приведены характеристики математики как «изучения» и как «конструирования». С одной стороны, из грамматической формы слов «изучение» и «конструирование» кажется понятным, что подразумеваются некоторые виды деятельности (деятельность, заключающаяся в изучении или конструировании). Но, с другой стороны, поскольку эти отнесения выражены при помощи названий непредельных видов человеческой активности и непонятийных конструкций, то возможно неоднозначное дальнейшее онтологическое уточнение того, что такое «изучение» и «конструирование». В зависимости от категориальной сетки исследователя, их можно свести не только к «деятельности», но и к таким альтернативным разновидностям человеческой активности, как «работа», «труд», «занятие», «времяпрепровождение» и др., в силу чего проясняющая ценность таких родовых отнесений как онтологических характеристик уменьшается. В предельном случае отнесение к слишком узкому роду может быть и совсем бесполезным с точки зрения онтологического прояснения. Так, характеризация математики или философии как «науки» ничего не добавляет к прояснению их онтологического статуса: с одной стороны, если принадлежность математики или философии к наукам проблематизируется, то речь обычно идет об их специфических, «видовых» признаках, не совместимых с отнесением математики и философии к науке; с другой же стороны, вся неопределенность с родовым отнесением науки переходит на математику или философию как одну из «наук». Аналогично и в ситуации с отнесением: «Математика могла бы быть определена и как вид искусства...» (Лолли, Сочков и Антаков, 2012: 72-73). Даже если согласиться с трактовкой философии как одной из частных наук или какой-то науки как «вида искусства», остается вопрос об их онтологическом прояснении. В общем случае речь должна идти об отнесении объектов, онтологический статус которых проясняется, к тому или иному типу объектов, задаваемому исходной онтологической картиной (мира в целом или исследуемой предметной области в частности). Именно это и будет методологически корректным «онтологическим отнесением».

\section{ПРИМЕРЫ НЕЯВНОЙ ТРАКТОВКИ \\ ФИЛОСОФИИ И НАУКИ КАК ЗНАНИЯ (CASE STUDIES)}

В литературе по истории и философии математики достаточно обычным является уклонение от прояснения ее онтологического статуса. Обычно ограничиваются лишь характеризацией ее как «науки». При 
этом часто одновременно допускаются высказывания, позволяющие их авторам одновременно приписать понимание математики и науки в целом и как «знания», и как «деятельности». В качестве иллюстрации рассмотрим некоторые примеры, авторы которых как-то затрагивали вопросы прояснения того, чем является математика, наука вообще или философия.

Одним из ярких примеров ситуации с пониманием и прояснением природы математики в соответствующей литературе является «Краткий очерк истории математики» голландско-американского историка математики Д. Я. Стройка (Стройк, Погребысский, 1984). В основном тексте книги нет ни одного иного прямого онтологического отнесения «математики», хотя имеется множество мест, в которых прямо и косвенно математика относится к наукам. Например: «Восточная математика возникала как прикладная наука...» (там же: 34), «Математика достигла, наконец, уровня настоящей науки благодаря тому новому мировоззрению, которое характерно для цивилизации греков» (там же: 49), «Это-образ, соответствующий тем условиям, в которых закладывались основы не только современной математики, но и всей современной науки и философии» (там же: 54), «Возможна ли математика как точная наука?» (там же: 6о), «Здесь более чем в какой-либо другой стране математику рассматривали как науку» (там же: 161). Еще больше мест, в которых трактовка математики как науки следует из контекста: «Эти краткие сведения из эпохи зарождения математики показывают, что наука в своем развитии не проходит обязательно все те этапы, из которых теперь складывается ее преподавание» (там же: 29), «Математика в виде головоломок часто существенным образом способствовала развитию науки, открывая для нее новые области» (там же: 88 прим.), «Только благодаря этому решение вопросов, относящихся к азартным играм, представляющим удобную и до сих пор используемую модель для анализа ряда понятий теории вероятностей, могло систематически привлекать внимание математиков и стать поводом для развития новой науки» (там же: 138), «И платоники, верившие в авторитет, и картезианцы, верившие в разум, считали математику царицей наук» (там же: 129), «Гаусс [...] широко применял математику к астрономии, к физике, к геодезии, вместе с тем он считал математику царицей наук, а теорию чисел-царицей математики» (там же: 178 прим.).

В предисловии к немецкому изданию только дважды можно найти что-то, что можно интерпретировать как родовое отнесение. Первое 
место: «Математика - широкое поприще идей, и ее история знакомит нас с некоторыми из благороднейших помыслов неисчислимых поколений» (Стройк, Погребысский, 1984: 10),- метафора, отсылающая нас, скорее, к эпистемической трактовке. Второе место: «...современная математика - настолько многосторонняя наука, что...» (там же), - не добавляет ничего к прояснению родового отнесения математики.

Эта ситуация отчасти исправляется в предисловии 1962 г. к русскому изданию, в котором Стройк критикует понимание истории математики как истории идей и настаивает на необходимости рассмотрения ее в контексте истории человеческой деятельности:

С самого начала я понял, что история математики - не только история развития понятий, но одна из частей истории человеческой деятельности ${ }^{4}$, в которой отражается борьба человека с природой, притом не абстрактного человека, а человека как члена общества. Однако большинство историков математики рассматривают ее почти исключительно как историю идей, понятий, переходящих от одного математика к другому, который их далее развивает. [...] Этот метод односторонен, но не ошибочен-он выявляет важные этапы в истории математики. Но при этом не выясняется, что существует тесная зависимость между математикой и общекультурными устремлениями эпохи, устремлениями, которые сами отражают, непосредственно или опосредствованно, преобладающие общественные и экономические условия (там же: $4^{-5}$ ).

Казалось бы, предисловие наполнено многочисленными местами, призывающими изучать историю математики в контексте социальной истории:

Мы должны стараться понять, каким образом общество влияет на точные науки, и это часто значительно углубляет наше понимание направлений, господствующих в этих науках. Конечно, верно, что общество, в котором развиваются университеты, поддерживает форму научной деятельности, когда можно жить в мире собственных идей. Но этот мир идей является своеобразным выражением нужд или тенденций эпохи (там же: 6).

Но автор тут же переходит на разговор о математике как о сфере мысли, идей:

Подобное явление в области чистой мысли было следствием огромного объема геометрических исследований в годы, последовавшие за французской революцией, и связанного с этим революционизирования математической мысли (там же).

43десь и в следующих цитатах из Стройка курсив мой.- - . Ш. 
Однако никогда мы не должны забывать, что сами идеи способны порождать новые идеи. Немало математических открытий было сделано в области отвлеченной мысли, когда какой-нибудь мыслитель оказывал влияние на своих коллег или учеников. В том, что математику описывают как постепенное развитие идей, то непрерывное, то скачкообразное, есть большая доля истины (Стройк, Погребысский, 1984: 7).

В целом Стройк не дает математике явной онтологической трактовки, которой он придерживался бы на протяжении всей книги. Но, хотя он постоянно пытается связывать историю математических знаний с социальной историей, текст его книги все же дает основания проинтерпретировать его понимание «математики» как эпистемическое, то есть трактующее ее как некоторые знания - даже без учета формы их организации. Во-первых, на это указывает ряд мест, которые имеют смысл только при интерпретации «математики» как «знаний»: «Если к элементарной математике отнести материал, входящий в...» (там же: 29-3о прим.); о папирусах: «Математика, которая в них изложена...» (там же: 37); «Математика „Девяти книг“ состоит в основном из задач и общих указаний, как их решать» (там же: 48). Во-вторых, на это же указывает сам подбор материала, поскольку начинать историю математики с «представлений о числе и форме» (там же: 21) эпохи палеолита также можно только при ее трактовке как некоторых знаний «о числе и форме».

Аналогичную ситуацию с непроясненностью природы философии и ее неявной трактовкой как некоторого знания можно найти в книге А. К. Сухотина «Философия математики» (Сухотин, 2004). Параграф «Определение философии. Разброс значений» (§ 1) главы «Предметная область философии математики» (гл. 1), как представляется, посвящен как раз нашей теме. Но все обсуждение в нем крутится вокруг «дилеммы», является ли философия наукой или же нет. Речь при этом идет в основном о «видовых» особенностях философии и ее отличиях от «других наук», как будто единственная проблема определения философии состоит в том, обладает ли она научностью и в какой степени. Хотя формально здесь поднимается вопрос об «отнесении к роду» (в данном случае, к «науке»), основная онтологическая функция отнесения не выполняется: не указывается тип, природа, способ существования объекта, поскольку «наука» требует онтологического прояснения в не меньшей степени, чем «философия». Правда, бегло приводятся и другие «определения» философии: философия как «мысль о мысли» (там же: 8) 
и как «учение об общем» (Сухотин, 2004: 9). Что с онтологической точки зрения значит понимание философии как «мысли»? Во-первых, «мысль» может пониматься как метафора «мышления», то есть «мысль о мысли» - это «мышление о мышлении». Это - деятельностное понимание философии. Во-вторых, - как знание, что дает нам эпистемическую трактовку философии. С первого взгляда напрашивается первое истолкование, нередко встречающееся у философов ${ }^{5}$. Но, учитывая контекст, нужно предпочесть второй вариант. Так, понимание философии как «учения»-это, безусловно, эпистемическая трактовка, отсылающая нас к знанию или системе знаний. С этим согласуется и заключительная трактовка Сухотина: дается ссылка на «определение» математики Р. Курантом и Г. Роббинсом, по мнению которых математика есть то, что изложено в их книге (Курант и Роббинс, Колмогоров, 2001) ${ }^{6}$, и по аналогии предлагается понимать философию. Кроме того, в этом же параграфе излагаются позитивистские представления о видах предложений, что имеет смысл только при трактовке науки и философии как знаний. Причем знания, видимо, отождествляются автором с истинными предложениями. Таким образом, реконструкция общей трактовки науки и философии в этой книге такова: наука-это знания (в лучшем случае, совокупность знаний) о чем-то, причем знания, взятые в форме их языкового представления - предложений. То есть наука - это некоторая совокупность предложений. А философия - это некоторая наука или, по крайней мере, она также является совокупностью знаний или предложений, хотя, возможно, и отвечающих некоторым иным требованиям, чем наука. Но в силу отсутствия в тексте какой-либо реальной определяющей процедуры автор путается даже с родовым

${ }_{5}^{5}$ Например, у А. М. Пятигорского и М. К. Мамардашвили. Так, в книге Пятигорского «Мышление и наблюдение» находим: «Философ применяет мышление к мышлению» (Пятигорский, 2002: 2); «Предмет этих лекций-обсервационная философия, то есть философия, занимающаяся наблюдением мышления. Точнее, наблюдением чего бы то ни было как мышления. Еще точнее, что бы она ни наблюдала, она это наблюдает как мышление» (там же: 4). Или в более сильной форме в его же книге «Что такое политическая философия: размышления и соображения»: «...философия, как я ее понимаю, не имеет и не может иметь своего конкретного специфического предмета, или это будет не философия, а наука. Философия в принципе [...] занимается не предметом, каков бы он ни был, а мышлением о предмете» (Пятигорский, 2007: 8); отвечая на вопрос «А не может быть мышление о предмете предметом философии?»: «Это и есть единственный предмет философии! Другого у нее нет» (там же: 9).

${ }^{6}$ Правда, у самих Куранта и Роббинса такого в точности утверждения нет, и их собственное понимание математики скорее предполагает трактовку ее как некоторой деятельности. 
отнесением и перескакивает с одного понимания на другое. Так, вопреки общему подходу в некоторых местах можно найти фразы, которые трактуют философию в некотором деятельностном смысле, например, во втором параграфе той же главы: «...философия - это особый тип миропостижения» (Сухотин, 2004: 11).

Если в этих двух взятых для примера книгах вопрос об онтологическом статусе философии и науки (здесь - математики) фактически так и не решается, то в основной части учебной и научной литературы он даже не поднимается. При этом часто сами тексты дают возможность предполагать, что их авторы склоняются к эпистемической трактовке науки и философии.

\section{ПРЕДПОСЫЛКИ И СЛЕДСТВИЯ}

ПОНИМАНИЯ ФИЛОСОФИИ И НАУКИ КАК ЗНАНИЯ

Рассмотрим предпосылки, коннотации и следствия, связанные с выбором онтологической трактовки науки и философии как знания. Основная возникающая здесь проблема связана с существованием «знаний о некотором предмете». Что значит, что в некоторой культуре $N$ существуют знания об $X$ и $Y$, если сами носители этой культуры таких знаний не выделяют или не различают друг от друга? Здесь может быть два подхода.

Первый подход состоит в том, что это именно для исследователя (в его культуре или даже только в системе его представлений) существуют такие предметные области, как $X$ и $Y$. И в соответствии с этими его представлениями он выискивает в культуре $N$ то, что может назвать «знанием об $X \gg$ и «знанием об $Y$ ». Это вполне законный ход, пока исследователь удерживает исходную познавательную рамку: это именно его представления об $X, Y$ и о том, что может быть названо «знанием об $X$ » и «знанием об $Y$ ». При этом на стыке материала данной культуры $N$ и исследовательской «оптики» возникает фантом (феномен, симулякр) наличия в данной культуре «знаний об $X \gg$ и «знаний об $Y$ ». В силу опасности онтологизации таких фантомов исследователь не имеет права утверждать, что в культуре $N$ существуют «знания об $X \gg$ и «знания об $Y »$ или, тем более, «наука об $X »$ и «наука об $Y »$, пока не покажет, что деление на предметные области $X$ и $Y$ и выделение «знаний об $X \gg$ и «знаний об $Y$ — как чего-то отличного друг от друга и от иных знаний - существует в самой культуре $N$ на уровне сознания (например, массово осознается самими представителями данной культуры или неявно навязывается им через соответствующую структуру 
культурообразующих текстов) и деятельности (например, за счет связи с разными практиками, ритуалами и т. п.) носителей данной культуры ${ }^{7}$. Нарушение же данной когнитивной рамки упускает этот фантом из-под контроля и ведет к его онтологизации. Такая незаконная, ошибочная онтологизация собственных представлений не имеет единого названия, хотя обсуждается в ряде областей логики и методологии. Так, в логике традиционно обсуждалось в качестве ошибки «гипостазирование» - приписывание реального существования объектам, представления о которых получены в результате абстрагирования свойств (белизна, добро, тяжесть, человек сам по себе и т.п.), на котором построена онтология средневекового реализма и вульгарного платонизма. В области логической методологии описана ошибка неявного, ненамеренного введения в теорию или предметную область новых объектов при помощи определений ${ }^{8}$. Проблема таких ошибок обсуждается как «креативность определений».

В рамках отечественной истории науки ошибка перенесения современных представлений о науке, ее структуре, формах организации, целях, концептуальном аппарате и т.д. в прошлое, на прежние периоды развития науки получила название «презентизм» ${ }^{9}$. Презентизмом будет, например, перенос современных представлений о науке на первобытные сообщества или на Античность. Но перенос «современных» представлений на прошлое и придание им там статуса существования является лишь частным случаем встречающихся исторических искажений, поскольку подобным образом могут переноситься вообще любые представления об устройстве общества (его институтах, обычаях и идеях) в одну эпоху на институты, обычаи и идеи другой эпохи. Такую

7 Правда, учета одной только деятельности может оказаться недостаточно. Например, можно ли считать «медицинскими знаниями» знания о том, что определенная трава снимает у человека некоторый эффект, считающийся негативным, если эти знания являются частью магических знаний шамана и действие этой травы осмысливается как воздействие духа или Силы данной травы на духов или Силу, вызвавших у человека тот негативный эффект, который нужно снять?

${ }^{8}$ Многие люди забывают, что определение вводит лишь новое понятие, и нет никакой гарантии, что в предметной области существует хотя бы один объект, подпадающий под это понятие. Существование такого объекта (а в случае единичных имен-и его единственность) нужно доказывать или (для эмпирических теорий и дискурсов) как-то иначе обосновывать. Без этого в теории может появиться объект, которого там изначально не было, то есть происходит неявное расширение теории. А в неформализованных дискурсах появляются, соответственно, фантомные объекты.

9 Обзор дискуссий на эту тему можно найти в (Кузнецова, 2009). 
ошибку принято называть анахронизмом. Пример анахронизма - перенос наших представлений о позднеклассических и эллинистических философских школах на досократиков, в частности, на милетскую традицию, связываемую с $Ф$ алесом ${ }^{10}$. Но и анахронизм - недостаточно общий случай для такой ошибки, поскольку точно такой же неправомерный перенос может осуществляться не только на какую-то культуру прошлого, но с одной современной культуры на другою, или с одной древней культуры на другую, синхронную ей. Пример такой ошибки находим в начале (кн. I, 1-2) «О жизни, учениях и изречениях знаменитых философов» Диогена Лаэртского, где тот пересказывает один из взглядов на возникновение философии, высказывавшихся в Античности (Диоген Лаэртский, Гаспаров, 1986: 55). Согласно этому мнению, философия впервые возникла в древние времена у других, окружавших греческий мир народов. Здесь общей ошибкой является перенос представлений греков о своей культуре и, в частности, о «философии» на культуры других народов. Одновременно с этим здесь имеется и ошибка презентизма, которая в данном случае лишь вытекает из общей ошибки неправомерного переноса культурных представлений, поскольку те социальные группы («гимнософисты», «маги», «халдеи», «друиды»), с которыми связывается философия у упоминаемых Диогеном народов, появились, как считалось, у этих народов существенно раньше, чем у греков возникла «философия». В основе всех этих ошибок лежит неправомерная онтологизация тех или иных представлений самого «интерпретатора», в силу чего возникают фантомные объекты и явления, исходно отсутствовавшие в соответствующих предметных областях.

Другой подход к оправданию выделения «знаний (о некотором предмете)» состоит в следующем. Даже если представители исследуемой культуры $N$ не выделяют и, следовательно, не отличают друг от друга «знаний об $X »$, «знаний об $Y$ » т. д., мы, тем не менее, можем говорить о наличии в $N$ подобных знаний и, соответственно, наук (при рассматриваемой трактовке наук как «знаний о...») в силу того, что деление мира на предметные области, или регионы, $X, Y$ и т. д. объективно или универсально задано, то есть не зависит от принадлежности к той

${ }^{10}$ Есть мнение, высказываемое, в частности, отечественным историком античной философии И. Н. Мочаловой, что такой же ошибкой являются распространенные представления о якобы возникающих сразу после смерти Сократа «сократических школах», поскольку как учебные заведения они возникают несколькими десятилетиями позже, уже под влиянием успехов Академии Платона. 
или иной культуре. Существование этих регионов может связываться со структурой мира (марксистские «формы движения материи», эмерджентистские уровни бытия и т. п.), универсальной (априорной) структурой человеческого сознания или разума (например, в смысле Канта) и т. п. С этой точки зрения можно утверждать, что в любых человеческих обществах существуют такие науки, как «ботаника», «зоология», «астрономия», «математика»- на том основании, что в мире в качестве отдельных групп существуют растения, животные, небесные явления, числа (или количества), а значит, и у представителей всех народов есть какие-то знания об этих предметах или о действиях над ними. В качестве следствий такой трактовки получаем: (1) универсальность базовых наук (они существуют в любых человеческих обществах, даже исключительно «примитивных»), (2) существование некоторой естественной системы наук, некоторые из которых просто еще не открыты или смешаны с другими науками, в то время как некоторые «науки», наоборот, являются мнимыми.

Если соответствующие онтологические или гносеологические постулаты фиксируют исходный общефилософский выбор исследователя, онтологическую или гносеологическую рамку его работы, то такой подход философски допустим. Но если они принимаются ad hoc, с целью обоснования права «исследователя» приписывать «изучаемой» им культуре явления и структуры, которые в ней как таковые не наблюдаются, то данный подход неприемлем.

Здесь мы встречаем характерную связку: говорить про «науку» в первобытных обществах можно только трактуя ее как «знание», а трактовка «науки» как «знания» (без каких-либо оговорок или ограничений) приводит нас к ее обнаружению в любых первобытных обществах. Из цивилизационно-типологической отнесенности науки и философии к первобытным сообществам получаются и основные следствия их трактовки как знания:

(1) датировка возникновения науки и философии задается датировкой возникновения человеческих обществ (возможно, даже не первобытных сообществ особей homo sapiens sapiens, а культур более древних гоминид);

(2) вопрос о национально-культурной локализации здесь не возникает, поскольку «наука» в таком понимании (по крайней мере, некоторые основные «науки»), равно как и философия, существует во всех человеческих обществах. 
Подобный подход к науке находим, например, в работе французского этнографа К. Леви-Стросса «Неприрученная мысль» (Le pensée sauvage), в которой имеется множество прямых и косвенных упоминаний о существовании науки в эпоху неолита и раньше. Например: «...как если бы необходимые связи, составляющие предмет всякой науки, будь то неолитическая или современная, могли постигаться двумя путями...» (Леви-Стросс, Островский, 1999: 125), «Человек неолита или протоистории является, следовательно, наследником длительной научной традиции» (там же). Такое понимание науки Леви-Строссом понятно, поскольку предметом его рассмотрения и анализа становятся «знания» (и «структуры знаний») отдельных первобытных племен, и одной из характерных идей Леви-Стросса является трактовка таких знаний как альтернативной науки. Относительно математики аналогичный подход находим, например, у Стройка в первой главе его «Очерка»: «Наши первоначальные представления о числе и форме относятся к очень отдаленной эпохе древнего каменного века- палеолита» (Стройк, Погребысский, 1984: 21).

В одном месте Леви-Стросс говорит также о «первобытном филосо$\oint e^{11} \gg(Л е в и-С т р о с с, ~ 1999: 123)$. В этом он, по-видимому, следует достаточно долгой традиции, распространенной среди этнографов, которые писали о «первобытной философии», понимая под этим совокупность или систему общих представлений первобытных народов о мире, человеке и т. п.:

Многие этнографы, считавшие, что всякое рассуждение о мире- философия, утверждали, что и «дикарь»-философ, так как размышляет о причинах различных явлений природы, о их зависимости друг от друга. Э. Тэйлор указывал в книге «Первобытная культура», что «мыслящие люди, стоящие на низшей ступени культуры», обладают «широкой философией природы». Д. Фрейзер так же, как и Э. Тэйлор, употреблял в труде «Золотая ветвь» понятие «первобытный философ» (Шахнович, 1971: 11) $)^{12}$.

В. Вундт в статье «Зачатки философии и философия первобытных народов» из сборника «Общая история философии» (СПб., 1910) «ссылался на то, что у различных племен имеются воззрения, которые, несмотря на всю свою примитивность, все-таки относятся $\kappa$ логике, психологии, этике и натурфилософии» (там же: 12). Австралийский

${ }^{11}$ Во всех цитатах этого и трех следующих абзацев курсив мой. - T. Ш.

${ }^{12}$ Цитаты из Тэйлора приводятся Шахновичем по: Тэйлор, Коропчевский, 1939: $265^{-266 .}$ 
этнограф А.П. Элькин уже в середине хх в. писал о «философских взглядах на жизнь и мир, которые проявляются в поведении, верованиях и обрядах австралийских аборигенов» (Элькин, Бровик и Михайлов, 1952: 174; цит. по: Шахнович, 1971: 13):

Австралийские аборигены выработали определенную систему взглядов на жизнь и вселенную, на прошлое, настоящее и будущее. Она находит выражение в их обрядах и мифах, в их общественном поведении и верованиях, относящихся как к самим людям (к рождению, смерти и сну), так и природе [...]. Австралийский философ имеет в своем распоряжении достаточно материала, чтобы упражнять на нем свои мыслительные и аналитические способности и удовлетворить стремление к систематизации и логическим построениям (Элькин, Бровик и Михайлов, 1952: 174; цит. по: Шахнович, 1971: 13).

Если наука понимается как знание или знания о каком-то предмете $X$ (при варьировании которого мы получаем разные науки), тем более (при лингвистической редукции) как совокупность истинных утверждений об этом $X$, то философию также достаточно естественно понимать как «науку». Правда, здесь возникают дополнительные проблемы.

Во-первых, философия, в отличие от наук, не может быть специфицирована по предмету (объекту) исследования. В поле ее интереса могут попадать самые неожиданные предметы, включая новые технологии (часовые и иные механические конструкции в XVII-XVIII вв., компьютерные, медицинские, ядерные в XX в.) или отдельные преступления и злодеяния (грехопадение, распятие Иисуса Христа, убийство сыновей Али Хасана и Хусейна, холокост и т. п.). Во-вторых, при таком знаниевом понимании философии теряется ее жизнетворческий и институциональный аспекты: философия возникает в Античности как особого вида практика сознательного и разумного выстраивания собственной жизни на основании некоторых жизненных идеалов ${ }^{13}$ и получает институциональное оформление как особый тип образования, связанный с философскими школами ${ }^{14}$, который к концу Античности становится, собственно, самим высшим общим образованием. Несмотря на все перипетии, трансформации и изменившиеся институциональные формы философии, эти аспекты до сих пор определяют ее понимание во всех культурах, напрямую или опосредованно перенявших философию у древних греков.

${ }^{13}$ См., например: Адо, Гайдамак, 1999.

${ }^{14} \mathrm{C}$., например: Шичалин, 2000. 


\section{ЗАКЛЮЧЕНИЕ}

Если мы не принимаем натурализма в выделении предметных областей, то для утверждения, что для культуры $N$ существуют предметные области $X_{1}, X_{2}, \ldots, X_{n}$, необходимо обнаружить соответствующее деление в сознании и практике самих носителей культуры $N$. Если же мы идем дальше и отказываемся от натурализма в выделении областей знания (или совокупностей знания), то для утверждения, что в культуре $N$ существует некоторая область знания $Y$ (или об $Y$ ), необходимо обнаружить в $N$ существование соответствующих уже сформировавшихся совокупностей, собраний этих знаний в таких формах, как тексты на соответствующие темы или институциализированные практики обучения знаниям именно из этой, а не иной области (например, в рамках обрядов посвящения). Формирование таких совокупностей связано с появлением систем устойчивого разделения труда (профессий) и письменности, то есть с новыми типами обществ. И если с первыми «подборками» знаний мы сталкиваемся еще в бесписьменных обществах в связи со специализацией колдунов или шаманов, то первые тексты, которые хотя бы по предметной области можно соотнести с современными науками, мы впервые находим в так называемых речных цивилизацияхдревнеегипетской, месопотамской и т.д.

Так, наиболее древние из известных текстов, которые можно связать с математикой, представлены в древнеегипетских папирусах эпохи Среднего царства: Московском (математическом) папирусе (ГМИИ им. А. С. Пушкина) и папирусе Ринда (Ахмеса) (Британский музей, частично - Нью-Йорк) (Ван дер Варден, Веселовский, 2007: 17-49). Здесь возникают свои вопросы. Например, можно ли считать эти папирусы «математическими» с точки зрения сознания представителей древнеегипетской культуры, если они были сформированы в рамках практики подготовки «писцов» - профессиональных чиновников (управленцев) - и, соответственно, представителями древнеегипетской культуры должны были пониматься как часть теории управления (что вполне вычитывается из некоторых дошедших до нас древнеегипетских писем-поучений $\left.{ }^{15}\right)$ ? И можно ли их считать «математическими» с точки зрения структуры, поскольку в них собраны примеры решения конкретных задач без каких-либо обобщений и, что более важно, без дедуктивного построения

${ }^{15}$ См., например, письмо из папируса Анастасии № 1 (Ван дер Варден, Веселовский, 2007: 20). 
математического знания (в терминологии древнегреческой культуры это іं 入оүıбткиं, искусство счета)?

Если же мы, как большинство современных историков математики, вводим дополнительное требование дедуктивного построения, то мы переходим к древнегреческой культуре. Но здесь встают новые проблемы, в частности, проблема существования единой области знания и исследования, которую мы могли бы соотнести с математикой. Так, на протяжении всей Античности мы видим отдельные дисциплинывначале «геометрию», чуть позже «арифметику», «гармонику» и «астрологию», к которым с IV в. до н. э. преимущественно и применяется

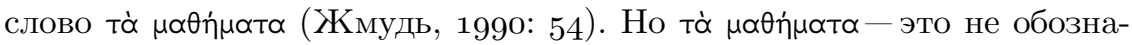
чение какой-то единой дисциплины, это собирательное обозначение наподобие современных выражений «гуманитарные науки» и «естественные науки», или даже еще более аморфно-наподобие того, как мы сегодня говорим об «искусствах». Впрочем, наметившееся в трудах и в школьной практике платоников ${ }^{16}$ объединение четырех указанных дисциплин в цикл однородных дисциплин та̀ $\mu \alpha \theta \dot{\eta} \mu \alpha т \alpha$ вряд ли можно однозначно считать состоявшимся. С одной стороны, сами слова «математика» и «математик» в поздней Античности, особенно на латинской почве, начинают использоваться как названия астрологии и астрологов в современном понимании этих слов (Thorndike, 1923: 6o, 209, 411, $\left.4^{6} 4^{-4} 65,513,520,524,532,534,536,632,670,710,711,744\right)$. С другой стороны, объединивший эти четыре дисциплины цикл quadrivium лег в основу образования именно в западноевропейских университетах, то есть существенно позже, причем существовал лишь в теории ${ }^{17}$. Тогда как византийская система высшего образования, послужившая прообразом европейских университетов, вообще не имела такой четкой теоретической структуры, какую приписывала концепция artes liberales.

Итак, отнесение (без каких-либо оговорок и дополнений) философии, науки и их различных частных дисциплин к «знанию» требует принятия некоторых предпосылок об универсальном и социально вечном, внекультурном характере членения мира на предметные области. Это, на взгляд автора, приемлемо только в том случае, когда эти предпосылки принимаются до и независимо от постановки вопроса о природе

\footnotetext{
${ }^{16}$ Особенно поздних - так называемых неоплатоников и неопифагорейцев. Об этом см., например: Адо, Шичалина, 2002: 77 .

${ }^{17}$ На практике набор дисциплин квадривиума мог достаточно сильно варьироваться и включать дисциплины, не имеющие к математике никакого отношения. Об этом см., например: Суворов, 1898: 149-150.
} 
философии и науки. Если же столь сильные онтологические постулаты принимаются лишь для того, чтобы ad hoc оправдать отнесение философии и науки к «знанию», то такой ход методологически неприемлем. При этом даже при принятии таких онтологических допущений остается без ответа вопрос о том, как «философия» и «наука», понимаемые таким образом, существуют в соответствующей культуре. Существуют ли такие «философия» и «наука» только в качестве наших мысленных объединений соответствующих знаний по признаку их отнесения к одной и той же предметной области, то есть существуют ли они лишь как мысленные конструкции интерпретатора? Или же в соответствующей культуре отдельные знания, относящиеся к одной и той же предметной области, как-то взаимосвязаны и образуют так или иначе организованные совокупности, системы знаний? Существуют ли в этой культуре некоторые особые, выделенные деятельности, практики, профессии или иные социальные статусы, направленные на построение таких знаний, относящихся к одной предметной области, или на манипуляцию с ними?

Если принимаются онтологические допущения о существовании соответствующих предметных областей, но сами знания, относящиеся к одной и той же предметной области, объединяются лишь в мышлении стороннего интерпретатора (исследователя), то корректно говорить о существовании в данной культуре соответствующих знаний, но нет оснований вводить представления о существовании в ней «философии» или «науки». Для корректного разговора о существовании в культуре «философии» или «науки» необходимо, как минимум, обнаружить в этой культуре соответствующие организованности знаний или особые целесообразные социальные активности по построению таких систем знаний. Но если принять такую поправку к употреблению слов «философия» и «наука», то нужно скорректировать и соответствующие понятия философии и науки и перейти к их трактовке как систем знания или как видов деятельности. Анализ сферы применимости таких трактовок, а также связанных с ними онтологических и гносеологических предпосылок - задача отдельного исследования.

\section{ЛИТЕРАТУРА}

Адо И. Свободные искусства и философия в античной мысли / пер. с фр. Е.Ф. Шичалиной. - М. : Греко-латинский кабинет, 2002. 
Адо П. Что такое античная философия? / пер. с фр. В. П. Гайдамака. - М. : Издательство гуманитарной литературы, 1999.

Ван дер Варден Б. Л. Пробуждающаяся наука : математика Древнего Египта, Вавилона и Греции / пер. с нидерл. И. Н. Веселовского. - М. : КомКнига, 2007. Диоген Лаэртский. О жизни, учениях и изречениях знаменитых философов / пер. с древнегреч. М. Л. Гаспарова. - М. : Мысль, 1986.

Жмудъ Л. Я. Пифагор и его школа. - Л. : Наука, 1990.

Кузнецова Н. И. Презентизм и антикваризм - две картины прошлого // Arbor Mundi. - 2009. - № 15 .

Курант P., Роббинс Г. Что такое математика? : элементарный очерк идей и методов : пер. с англ. / под ред. А.Н. Колмогорова. - М. : МЦНМО, 2001. Леви-Стросс K. Неприрученная мысль // Первобытное мышление / пер. А. Островского. - М. : Терра - Книжный клуб, Республика, 1999. - С. 111-336. Лолли Г. Философия математики : наследие двадцатого столетия / под ред. Я. Д. Сергеева ; пер. с итал. А. Л. Сочкова, С. М. Антакова. - Нижний Новгород : Изд-во Нижегородского ун-та, 2012.

Никифоров А. Л. Философия и история науки. - М. : Идея-Пресс, 2008.

Пятигорский $A . M$. Мышление и наблюдение : четыре лекции по обсервационной философии. - Рига : Liepnieks \& Ritups, 2002.

Пятигорский A. М. Что такое политическая философия: размышления и соображения : цикл лекций. - М. : Европа, 2007.

Сойер У. У. Прелюдия к математике / пер. с англ. М. Л. Смолянского, С.Л. Романовой. - М. : Просвещение, 1972.

Стройк Д. Я. Краткий очерк истории математики / пер. с нем. И. Б. Погребысского. - М. : Наука, 1984.

Суворов Н. С. Средневековые университеты. - М. : Типолитогр. т-ва И.Н. Кушнерев и $\mathrm{K}^{\circ}, 1898$.

Сухотин A.K. Философия математики : учебное пособие / под ред. В. А. Суровцева. - Томск : Изд-во Томск. ун-та, 2004.

Тэйлор Э. Первобытная культура / пер. с англ. Д. Л. Коропчевского. - М. : Государственное социально-экономическое издательство, 1939.

Шахнович М. И. Первобытная мифология и философия : предыстория философии. - Л. : Наука, 1971.

Шичалин Ю. А. История античного платонизма в институциональном аспекте. М. : Греко-латинский кабинет, 2000.

Элькин А. Коренное население Австралии / пер. с англ. Л. Я. Бровика, В. П. Михайлова. - М. : Издательство иностранной литературы, 1952.

Goodman N. D. Mathematics as an Objective Science // American Math. Monthly. 1979. - Vol. 86, no. 7. - P. 540-551.

Kline M. Mathematics in Western Culture. - Oxford : Oxford University Press, 1953. Thorndike L. A History of Magic and Experimental Science during the First Thirteen Centuries of Our Era. Vol. 1. - New York : Columbia University Press, 1923. 
Shiyan, T. A. 2017. "O traktovke filosofii i nauki kak 'znaniya' v kontekste ikh ontologicheskoy kharakteristiki [On the Interpretation of Philosophy and Science as 'Knowledge' in the Context of Their Ontological Characteristics]" [in Russian]. Filosofiya. Zhurnal Vysshey shkoly ekonomiki [Philosophy. Journal of the Higher School of Economics] I (3), 80-104.

\title{
TARAS SHIYAN
}

PhD in Philosophy; Associate Professor of the Chair of the Sociology of Management, Department of Philosophy and Sociology, Institute of the Social Sciences, Russian Presidential Academy of National Economy and Public Administration (Moscow); Associate Professor of the Chair of Philosophy, Department of Theology, St. Tikhon's OrthodoX University For Humanities (MOSCOW)

\section{On the Interpretation of Philosophy and Science AS "KNOWLEDGE" IN THE CONTEXT of Their Ontological Characteristics}

\begin{abstract}
The first and the most important step in the determination of any object of thinking is specifying what type of objects of known nature the object is assigned to. The author calls this operation "assignment to a genus" generally and "ontological assignment" in the narrow sense of being used to specify (clarify) the ontological status of the object. In the case of clarifying the nature of philosophy, mathematics, science in general, or other particular sciences and scientific disciplines there are four main ontological attributions: understanding them as a knowledge, as a sphere, an area of knowledge, as a kind of activity and as a sphere of activity (as a social institution). Each of these interpretations is associated with the adoption of some ontological and epistemic premises and conclusions about time, place and circumstances of the genesis of philosophy and sciences. This article demonstrates general principles of the author's approach and analyzes the first of the marked interpretations of the nature of philosophy and sciences: their interpretation as knowledge. This interpretation is most widespread, but it is usually unexplicated. Nevertheless, the interpretation is connected with making the strongest ontological assumptions about existence of the extra-cultural and extra-historical forms of knowledge and the most radical historical-cultural conclusions about the presence of philosophy and science in all human societies and at all times. This paper is focused on the interpretation of nature and genesis of mathematics, whose history is closely connected with philosophy, science and many fields of practice.
\end{abstract}

Keywords: Science, Mathematics, Ontology, Assignment to a Genus, Ontological Assignment, Knowledge, Sphere of Knowledge, Sphere of Activity, Social Institute, Primitive Society.

\section{REFERENCES}

Ado, I. [Hadot, I.] 2002. Svobodnyye iskusstva i filosofiya v antichnoy mysli [Arts libéraux et philosophie dans la pensée antique] [in Russian]. Trans. from the French by Ye.F. Shichalina. Moskva [Moscow]: Greko-latinskiy kabinet.

Ado, P. [Hadot, P.] 1999. Chto takoye antichnaya filosofiya? [Qu'est-ce que la philosophie antique?] [in Russian]. Trans. from the French by V. P. Gaydamak. Moskva [Moscow]: Izdatel'stvo gumanitarnoy literatury.

Diogen Laert.skiy [Diogenes Laërtius]. 1986. O zhizni, ucheniyakh $i$ izrecheniyakh znamenitykh filosofov [Lives and Opinions of Eminent Philosophers] [in Russian]. Trans. from the Ancient Greek by M. L. Gasparov. Moskva [Moscow]: Mysl'. 
El'kin, A. [Elkin, A.] 1952. Korennoye naseleniye Avstralii [The Australian Aborigines: How to Understand Them] [in Russian]. Trans. from the English by L. Ya. Brovik and V.P. Mikhaylov. Moskva [Moscow]: Izdatel'stvo inostrannoy literatury.

Goodman, N.D. 1979. "Mathematics as an Objective Science." American Math. Monthly 86 (7): 540-551.

Kline, M. 1953. Mathematics in Western Culture. Oxford: Oxford University Press.

Kurant, R. and G. Robbins [Courant, R. and H. Robbins]. 2001. Chto takoye matematika? [What is Mathematics?]: elementarnyy ocherk idey i metodov [An Elementary Approach to Ideas and Methods] [in Russian]. Ed. by A. N. Kolmogorov. Moskva [Moscow]: MTsNMO.

Kuznetsova, N. I. 2009. "Prezentizm i antikvarizm-dve kartiny proshlogo [Presentism and Antiquarism as Two Pictures of the Past]" [in Russian]. Arbor Mundi, no. 15.

Levi-Stross, K. [Lévi-Strauss, C.] 1999. Nepriruchennaya mysl' [La Pensée sauvage] [in Russian]. In Pervobytnoye myshleniye [Primitive Mentality], trans. by A. Ostrovskiy, 111-336. Moskva [Moscow]: Terra-Knizhnyy klub / Respublika.

Lolli, G. 2012. Filosofiya matematiki [Filosofia della matematica]: naslediye dvadtsatogo stoletiya [L'eredità del novecento] [in Russian]. Ed. by Ya. D. Sergeyev. Trans. from the Italian by A. L. Sochkov and S. M. Antakov. Nizhniy Novgorod: Izd-vo Nizhegorodskogo un-ta.

Nikiforov, A. L. 2008. Filosofiya i istoriya nauki [Philosophy and History of Science] [in Russian]. Moskva [Moscow]: Ideya-Press.

Pyatigorskiy, A. M. 2002. Myshleniye i nablyudeniye [Thought and Observation]: chetyre lektsii po observatsionnoy filosofii [Four Lectures on Observing Philosophy] [in Russian]. Riga: Liepnieks \& Ritups.

- . 2007. Chto takoye politicheskaya filosofiya: razmyshleniya i soobrazheniya [What is Political Philosophy]: tsikl lektsiy [Reflections and Considerations] [in Russian]. Moskva [Moscow]: Yevropa.

Shakhnovich, M.I. 1971. Pervobytnaya mifologiya i filosofiya [Primordial Mythology and Philosophy]: predystoriya filosofii [Prehistory of Philosophy] [in Russian]. Leningrad: Nauka.

Shichalin, Yu. A. 2000. Istoriya antichnogo platonizma $v$ institutsional'nom aspekte [History of Antique Platonism: Institutional Aspect] [in Russian]. Moskva [Moscow]: Greko-latinskiy kabinet.

Soyyer, U. U. [Sawyer, W.W.] 1972. Prelyudiya $k$ matematike [Prelude to Mathematics] [in Russian]. Trans. from the English by M. L. Smolyanskiy and S. L. Romanova. Moskva [Moscow]: Prosveshcheniye.

Stroyk, D. Ya. [Struik, D. J.] 1984. Kratkiy ocherk istorii matematiki [Abriss der Geschichte der Mathematic] [in Russian]. Trans. from the German by I. B. Pogrebysskiy. Moskva [Moscow]: Nauka.

Sukhotin, A. K. 2004. Filosofiya matematiki [Philosophy of Mathematics]: uchebnoye posobiye [A Tutorial] [in Russian]. Ed. by V. A. Surovtsev. Tomsk: Izd-vo Tomsk. un-ta.

Suvorov, N.S. 1898. Srednevekovyye universitety [Medieval Universities] [in Russian]. Moskva [Moscow]: Tipolitogr. t-va I. N. Kushnerev i K.

T.eylor, E. [Tylor, E.] 1939. Pervobytnaya kul'tura [Primitive Culture] [in Russian]. Trans. from the English by D.L. Koropchevskiy. Moskva [Moscow]: Gosudarstvennoye sotsial'no-ekonomicheskoye izdatel'stvo.

Thorndike, L. 1923. A History of Magic and Experimental Science during the First Thirteen Centuries of Our Era. Vol. 1. New York: Columbia University Press. 
Van der Varden, B. L. [Van der Waerden, B. L.] 2007. Probuzhdayushchayasya nauka [Ontwakende wetenschap]: matematika Drevnego Yegipta, Vavilona i Gretsii [Egyptische, Babylonysche en Griekse wiskunde] [in Russian]. Trans. from the Dutch by I. N. Veselovskiy. Moskva [Moscow]: KomKniga.

Zhmud', L. Ya. 1990. Pifagor i yego shkola [Pythagoras and His School] [in Russian]. Leningrad: Nauka. 